\title{
Using Internet Streamed Data for Sport Visualization
}

\author{
Rex G Cammack, Paul Hunt
}

Department of Geography University of Nebraska Omaha, rcammack@unomaha.edu Department of Geography University of Nebraska Omaha, phunt@unomaha.edu

* Corresponding author

Keywords: Internet Mapping, Sports Mapping, Data Scrapping, Dynamic Display

\begin{abstract}
:
In many modern sports, athlete tracking for athlete performance analysis is a common practice. Most of the time this athlete tracking is done during training sessions. At some World Tour cycling races the broadcasting company and race organizers use athlete tracking data during race events for various graphical for fans of the sport. This research attempt to use the race real time broadcast of data to produce a web mapping application that will show detailed cycling race tactics and other mapping forms in near real time. This research focuses on data flow and processing for dynamic mapping of complex point data patterns.
\end{abstract}

